\title{
Da filosofia à psicopatologia: interlocuções entre Merleau-Ponty e Arthur Tatossian
}

\author{
From philosophy to psychopathology: dialogues between Merleau-Ponty and Arthur Tatossian
}

\author{
Juliana Lima de Araújo ${ }^{1}$, Anna Karynne Melo², Virginia Moreira ${ }^{3}$
}

\begin{abstract}
Resumo
Partindo das noções de percepção e ambiguidade, tomamos a fenomenologia de Merleau-Ponty para refletir sobre a relação entre homem e mundo na psicopatologia fenomenológica de Arthur Tatossian. Para esses autores, não devemos substituir o estudo do mundo ou da consciência pelo ser pensado, não separando o observador daquilo que está sendo observado, na medida em que buscamos o mundo vivido que se constrói em tal relação. Observamos que, assim como a fenomenologia ambígua de Merleau-Ponty intencionou romper a cisão entre as dimensões da objetividade e da subjetividade através da noção de Lebenswelt, Tatossian pensou ser indispensável o contato com o outro visando alcançar o Lebenswelt, o mundo vivido de cada um, compreendendo que as teorias construídas sobre as manifestações psicopatológicas não se dão a partir da experiência, mas na experiência.
\end{abstract}

Palavras-chave: Merleau-Ponty. Fenomenologia. Psicopatologia fenomenológica. Arthur Tatossian

\begin{abstract}
Starting from the notions of perception and ambiguity, we take Merleau-Ponty's phenomenology to reflect on the interrelation between man and world in the phenomenological psychopathology of Arthur Tatossian. For these authors, we should not replace the study of the world or consciousness with what is being thought, i.e., we should not separate the observer from what is being observed, as we seek the living world that is constructed in such an interrelation. As in the ambiguous phenomenology of Merleau-Ponty, who sought to disrupt the split between the dimensions of objectivity and subjectivity, through the notion of Lebenswelt, Tatossian thought that contacting each other is essential for us to achieve the Lebenswelt, each one's lived world, realizing that the theories built on the psychopathological manifestations do not come about from the experience but in the experience.
\end{abstract}

Keywords: Merleau-Ponty. Phenomenology. Psychopathology phenomenological. Arthur Tatossian

\footnotetext{
${ }^{1}$ Universidade de Fortaleza - Unifor - Fortaleza (CE). Brasil. E-mail: julianalimaaraujo11@ gmail.com

${ }^{2}$ Universidade de Fortaleza - Unifor - Fortaleza (CE). Brasil. E-mail: karynnemelo@ unifor.br

${ }^{3}$ Universidade de Fortaleza - Unifor - Fortaleza (CE). Brasil. E-mail: virginiamoreira@ unifor.br

Recebido: $21 / 02 / 2018$

Aceito: 30/04/2018
} 


\section{Introdução}

A fenomenologia é a principal perspectiva filosófica que sustenta uma ruptura com a lógica determinista, tanto em relação à filosofia metafísica quanto em relação às ciências positivas, ao buscar conhecer o homem e o mundo a partir da descrição dos fenômenos, construindo um novo paradigma que não se restrinja a um olhar causalista (Schneider, 2009). O campo da psicopatologia fenomenológica surge mergulhado nesse contexto, com a introdução da obra de Edmund Husserl pelos psiquiatras Ludwig Binswanger e Eugene Minkowski, no início na década de 1920.

Outro filósofo que traz contribuições importantes para a área da psicopatologia fenomenológica é Merleau-Ponty (1945/2011; 1964/2012). Ao tomar como fio condutor a noção de Lebenswelt, discutida na filosofia de Husserl, priorizou a reflexão sobre a relação homem e mundo, pensando-os de modo interligado, um não podendo existir sem o outro. Ao buscar superar o dualismo mundoconsciência ou corpo-espírito da tradição filosófica, compreendia que a filosofia era um movimento constante de questionamentos, pois pensava não ser possível alcançar uma verdade absoluta e nem acreditava na existência de uma consciência apartada do mundo. A filosofia seria, então, uma via de acesso para chegar ao mundo vivido de cada indivíduo, compreendendo homem e mundo sempre a partir de sua facticidade (Moreira, 2007; Tatossian, \& Moreira, 2012).

Arthur Tatossian, psiquiatra francês, situou a fenomenologia como uma base estruturante que volta seu olhar para a experiência, permitindo ir além do pensamento dualista para chegar a uma compreensão ambígua da relação homem e mundo. A relação entre a fenomenologia e a experiência psicopatológica será sempre de implicação e não de aplicação, na medida em que visa compreender seus processos constituintes, e não apenas descrever o mundo, pois "a fenomenologia não se interessa pelas realidades como tais, mas pelas suas condições de possibilidade" (Tatossian, 1979/2006, p. 25).

Neste artigo, temos como objetivo discutir a fenomenologia da percepção e da ambiguidade na filosofia de Merleau-Ponty (1945/2011; 1964/2012), na sua problematização da relação homem e mundo em diálogo com a psicopatologia fenomenológica de Tatossian (1979/2006; 1980/2012; 1997/2001). Partimos do entendimento de que, assim como na fenomenologia de Merleau-Ponty, a psicopatologia fenomenológica de Tatossian também visa o fenômeno na relação homem e mundo, transitando de uma posição objetiva para um mundo pré-predicativo, buscando pensar os entes antes deles terem sido pensados.

\section{A fenomenologia da percepção em Merleau-Ponty}

O conceito de percepção marca a obra de Merleau-Ponty (1945/2011) em sua fase existencial, partindo da perspectiva da consciência para alcançar o corpo experienciado, nomeado por ele de corpo próprio. O filósofo compreendia a percepção como apenas possível de ser construída junto com o que era percebido, sendo este percebido somente acessível através da percepção, não sendo algo restrito aos objetos e nem apenas inerente ao sujeito. A relação mútua entre sujeito e mundo aparece como tese que sustenta sua filosofia, na medida em que o mundo não é tomado como aquilo que se pensa, mas, o que se vive.

Merleau-Ponty (1945/2011) construiu sua filosofia partindo de um, até então, novo paradigma filosófico: olhar e considerar o todo. Com isso, ampliou o modo de pensar causalista que se centrava apenas nas relações de causa e efeito e que, segundo Merleau-Ponty, reduzia o corpo a instrumento: 
"enquanto o corpo vivo tornava-se um exterior sem interior, a subjetividade tornava-se um interior sem exterior, um espectador imparcial" (p. 88). Uma das importantes dicotomias apontadas pelo filósofo foram as noções de interioridade e de exterioridade. Assinalou que, caso o homem se relacionasse com os fenômenos a partir dessas noções, poderia acabar por funcionar de modo bem delimitado restringindo o entendimento do que seria externo a apenas aquilo que seria próprio ao mundo, e o interno aquilo que não seria visível, situando-o em um domínio da subjetividade. Ao refutar tal concepção dicotômica, afirmou ser impossível precisar onde começam e terminam os limites entre o homem e o mundo. Isto acaba por levar a implicações em como os indivíduos experienciam suas subjetividades e o que tomam por objetividade.

Para Merleau-Ponty (1945/2011), "a aquisição mais importante da fenomenologia foi, sem dúvida, ter unido o extremo subjetivismo ao extremo objetivismo em sua noção do mundo ou da racionalidade" (p. 18). Sua fenomenologia defende a unidade da experiência, refletindo-a de uma maneira que se afasta do campo das representações, buscando na própria existência os meios para pensá-la e compreendê-la. Para ele, a percepção está profundamente relacionada à corporeidade, ao sujeito encarnado, que é expressão da própria existência, na medida em que atravessa o campo dos sentidos.

Sua compreensão fenomenológica da percepção está em constante diálogo com os trabalhos do pintor Paul Cézanne. Ao se afastar de uma filosofia reflexiva da consciência, o filósofo compreendeu a relação homem e mundo a partir do campo do sensível, apontando semelhanças entre sua filosofia e a pintura de Cézanne (Moreira, 2007). Merleau-Ponty (1945/2004) refletiu sobre a ruptura de dicotomias, construindo uma fenomenologia situada no pré-reflexivo, aquém da dicotomia entre sujeito e objeto. Apontava que a pintura de Cézanne imprimia uma aproximação com o mundo através da impressão imediata que tinha dele, somente através do contato com a natureza construiria um caminho para expressá-la, afastando-o de um trabalho de ateliê. $\mathrm{O}$ artista pintava o mundo tal como este lhe aparecia, na perspectiva da sua experiência, quando as imagens estavam em vias de se constituir, não se propondo expor uma representação da realidade.

A percepção se apresenta como uma unidade entre o sensório e o motor, e o corpo, do qual fala Merleau-Ponty, é integração do indivíduo com o mundo. A linguagem também se situa nesse entrelaçamento homem-mundo, sendo expressão do corpo no mundo. Qualquer ato perceptivo fala e desperta no indivíduo algo, ao mesmo tempo, particular e subjetivo, mas, também, universal, na medida em que estas dimensões não podem ser vividas separadamente (Merleau-Ponty, 1945/2011). Dessa forma, a percepção é sempre corpórea, não podendo ser tomada como objeto puro, seja do pensamento ou do mundo (Furlan, \& Bocchi, 2003). Merleau-Ponty (1945/2011) situou a percepção como um campo em que as relações da existência se dão. No momento em que se percebe algo, não são os atributos do ambiente e do ente percebido que lhe são apreendidos, mas suas possibilidades de ação. A percepção é também o meio em que é formada a própria experiência humana, se constituindo como uma experiência primeira.

A percepção se situa em um fundo inesgotável, não sendo um ato de entendimento, pois afirma mais coisas do que realmente as apreende. $\mathrm{O}$ que se busca é, justamente, o que está no domínio préobjetivo. O filósofo apresenta como exemplo de entendimento a figura de um quadrado, que, possuindo características que o nomeiam enquanto tal, sempre será um quadrado, independentemente de estar situado em uma de suas bases ou em um de seus vértices. Já a percepção somente ganha significados quando olhada em relação com o que é percebido, não possuindo atributos que falem dela de modo independente. Merleau-Ponty (1945/2011) afirmou que não é possível alcançar algo através 
da percepção sem considerarmos que há alguém que perceba, só é possível percebermos as coisas na medida em que as experienciamos, pois

o percebido não é necessariamente um objeto presente diante de mim como termo a conhecer, ele pode ser uma "unidade de valor" que só me está presente praticamente. Se retiraram um quadro de um cômodo que habitamos, podemos perceber uma mudança sem saber qual (p. 430).

Para o filósofo, alcançamos a percepção partindo das sensações, com o intuito de explorar a nós mesmos no mundo. O que nomeia de sensação "é apenas a mais simples das percepções e, enquanto modalidade da existência, ela não pode, assim como nenhuma percepção, separar-se de um fundo que, enfim, é o mundo" (p. 324). Ao nos lançarmos no mundo, experienciamos uma consciência intencional, sendo uma consciência sempre voltada para algo, aberta ao mundo e aos outros. MerleauPonty discute em sua obra, especificamente na Fenomenologia da percepção, que toda consciência, enquanto ato de significação, não existe fechada em si mesma, assim como, se pensarmos a consciência perceptiva de forma absoluta, saímos do âmbito da experiência para recair em uma consciência que não pode ser apreendida diretamente, sendo, portanto, representada. Permanecer no campo das representações impediria uma compreensão do viver com, contemplando a singularidade de cada vivido, mantendo-se em um falar sobre, em uma postura distante e reducionista.

Para Merleau-Ponty (1945/2011), tanto a percepção das coisas quanto a percepção do corpo próprio "são duas faces de um mesmo ato" (p. 276), possuindo "necessariamente a mesma modalidade existencial, já que não se poderia separar da percepção a consciência que ela tem” (p. 500). Para o sujeito, o alcance do mundo fenomenológico somente acontece na sua experiência vivida e o ato de conhecer se realiza nos horizontes abertos pela percepção. Seu corpo próprio considera o entorno, e este, não sendo objeto, funciona como meio de comunicação com o mundo. Buscar alcançá-lo através de uma racionalização é uma tentativa fracassada, visto que

a experiência do corpo próprio opõe-se ao movimento reflexivo que destaca o objeto do sujeito e o sujeito do objeto, e que nos dá apenas o pensamento do corpo ou o corpo em ideia, e não a experiência do corpo ou o corpo em realidade (p. 269).

O corpo é "textura comum" (p. 315), estando presente em todos os objetos, o que possibilita uma aproximação com eles. A existência do corpo próprio é absoluta e funciona como um fundo em meio a presença passageira dos objetos. Há várias maneiras de ser corpo, assim como há vários modos de ser consciência. A consciência que temos do corpo se dá através do mundo, assim como temos consciência do mundo por meio do corpo. Sentir o mundo nos coloca como referência primeira, percebendo os objetos sob a nossa forma de experienciar o mundo.

Meu corpo, dizia-se, é reconhecível pelo fato de me dar "sensações duplas": quando toco minha mão direita com a mão esquerda, o objeto mão direita tem esta singular propriedade de sentir, ele também [...]. Quando pressiono minhas mãos uma contra a outra, não se trata então de duas sensações que eu sentiria em conjunto, como se percebem dois objetos justapostos, mas de uma organização ambígua em que as duas mãos podem alternar-se na função de tocante e de tocada (Merleau-Ponty, 1945/2011, p. 137). 
Desta maneira, a percepção já é concebida como ambígua. A mão que toca sente que a outra mão também pode, além de ser tocada, tocar. O corpo é percebido pelo sujeito como formado por partes que estão envolvidas e entrelaçadas, e não por partes separadas que estão justapostas. Para MerleauPonty (1945/2011), "meu corpo inteiro não é para mim uma reunião de órgãos justapostos no espaço. Eu o tenho em uma posse indivisa e sei a posição de cada um de meus membros por um esquema corporal" (p. 143). O todo, assim, não é a soma das partes. O esquema corporal fala da relação consigo e da relação com o outro, não sendo algo passível de ser percebido, pois é anterior à percepção explícita. O movimento e o fundo do qual ele se destaca estão intimamente ligados, pois os movimentos realizados pelo corpo não se dão em um espaço "vazio" e dissociados dos indivíduos. Nosso corpo habita as dimensões do espaço e do tempo, ele só o é no espaço, não podendo ser considerado fora dele.

A presença humana está totalmente misturada ao mundo. Sem este, é impossível a existência do ser humano, por mais que exista, a princípio, independente de nós, ele não está totalmente constituído, pois depende de nossas ações. Ao mesmo tempo que formamos o mundo, somos também por ele formados, em um movimento ambíguo que se constrói no horizonte da experiência. Compreendemos que, para Merleau-Ponty (1945/2011), somente é possível pensarmos o mundo e os entes ao experienciarmos cada relação, sem desconsiderar como somos ao mesmo tempo constituídos e constituintes também pela história e pela linguagem, que intervém fornecendo significações possíveis ao sujeito para aquilo que é vivenciado.

No contato com o outro experienciamos um mundo em comum que nos permite uma compreensão de nós mesmos através da linguagem.. A comunicação ocorre, em primeiro lugar, com o sujeito que fala e não com seu pensamento. É nesse sentido que se constitui o mundo fenomenológico, anterior à experiência reflexiva e se anunciando como estreitamente ligado à própria condição em que se encontra o sujeito na experiência (Merleau-Ponty, 1945/2011). Essa existência do homem no mundo se realiza através de sua corporeidade, constituída por um conjunto de significações experienciadas por cada indivíduo, e não objeto para um eu penso. É campo de presença repleto de potencialidades, e tem, através do seu movimento, uma intencionalidade que se volta ao mundo como totalidade aberta, cuja síntese não pode ser acabada e não como "um sistema de objetos dos quais fazemos a síntese, mas como um conjunto aberto de coisas em direção às quais nós nos projetamos" (Merleau-Ponty, 1945/2011, p. 518).

A vida perceptiva do corpo realiza a abertura primeira para o mundo, não funcionando como um objeto situado em uma relação de causalidade que teria como propósito explicar o mundo. $\mathrm{O}$ ato de ver se dá através da própria percepção, que possibilita o alcance da noção do que são os entes. Ao compreender a percepção como algo que está além do que pode ser observado, não estando restrito ao campo do visível, Merleau-Ponty (1964/2012), em seus últimos escritos, especificamente em sua obra póstuma $O$ visível e o invisível, fala de uma fé perceptiva que incorpora uma certeza, mas que "não se trata de pôr a fé perceptiva no lugar da reflexão mas, ao contrário, de abarcar a situação total que comporta reenvio de uma a outra" (p. 43). Através da fé perceptiva, os indivíduos passam a se relacionar com o mundo para além de provas, não sendo necessário a comprovação objetivista de algo para que seja vivido enquanto possibilidade.

A reflexão filosófica construída por Merleau-Ponty se volta para o mundo atravessado pela percepção, na busca por compreender os significados vivenciados. Mais do que viver uma experiência, o homem é a própria experiência, na medida em que se comunica com o mundo, com seu corpo e com os outros, não se colocando como que ao lado deles, mas sendo com eles. A filosofia não trataria mais o homem 
e o mundo como incógnitas, não os entendendo como termos conhecidos, que ao terem suas relações analisados chegaria a uma filosofia do conhecimento. Termos como atos de consciência, estados de consciência e mesmo percepção deixam de ser usados pelo último Merleau-Ponty (1964/2012), compreendendo que "a filosofia não é, ademais, tomada de consciência" (p. 101), o pensamento não está em uma consciência, mas no corpo.

\section{A fenomenologia da ambiguidade em Merleau-Ponty}

Tudo aquilo que pode ser alcançado pela experiência é formado por uma infinidade de olhares que se entrecruzam, compondo uma totalidade permeada pelo que Merleau-Ponty (1945/2011) nomeou de ambiguidade. Cada olhar alcança um ângulo do que está sendo observado, mesmo que vise o todo, sendo que o "próprio do percebido é admitir a ambiguidade, o 'movido', é deixar-se modelar por seu contexto" (Merleau-Ponty, 1945/2011, p. 33). Ao fazer distinção entre o corpo vivido da experiência e o corpo objetivo da ciência, o filósofo não os considerava de forma dualista, na medida em que não são duas dimensões separadas, mas um mesmo corpo descrito sob perspectivas diferentes. Tal descrição passa por uma experiência ambígua, uma vez que o corpo vivido não é somente um pensar sobre o corpo ou as ideias que se têm acerca dele, sendo, também, um movimento reflexivo, construindo sentidos sobre esse vivido que permanecem sempre abertos e são tomados em sua ambiguidade.

Merleau-Ponty (1964/2012) avançou em sua própria compreensão da relação homem e mundo, partindo de uma noção de consciência, presente na Fenomenologia da percepção, para desenvolver uma noção de carne, discutida principalmente na obra $O$ visível e o invisível. Com seu conceito de carne, buscou construir um caminho de entendimento da relação entre homem e mundo que escaparia do plano da representação, afirmando que "a filosofia reflexionante substitui o mundo pelo ser pensado" (p. 51). Para o filósofo, a carne

não é matéria, não é espírito, não é substância. Seria preciso, para designá-la, o velho termo "elemento" no sentido em que era empregado para falar-se da agua, do ar, da terra e do fogo, isto é, no sentido de uma coisa geral, meio caminho entre o indivíduo espacio-temporal e a ideia, espécie de princípio encarnado que importa um estilo de ser em todos os lugares onde se encontra uma parcela sua. Neste sentido, a carne é um "elemento" do Ser (p. 136).

Merleau-Ponty (1964/2012) resgatou o termo "elemento" no sentido que era empregado pelos pensadores pré-socráticos ao falarem de um princípio (arché) como a fonte e o sustentáculo permanente de todas as coisas. Para o filósofo, a carne é um elemento constitutivo, há uma simultaneidade de ser sujeito e objeto, visando alcançar a significação única de cada vivido. Entre o eu e o mundo não há um vazio, mas uma "espessura da carne" (p. 132), existindo uma mútua constituição. Ao questionar “onde colocar o limite do corpo e do mundo, já que o mundo é carne?" (p. 134), Merleau-Ponty compreendeu que a carne se dá no encontro entre momentos em que ao mesmo tempo que toco sou tocado, "um verdadeiro tocar o tocar, quando minha mão direita toca minha mão esquerda apalpando as coisas, pelo qual o sujeito que toca passa ao nível do tocado, descendo às coisas, de sorte que o tocar se faz no meio do mundo e como nelas" (p. 130).

O conceito de carne em Merleau-Ponty (1964/2012) nasce em direção à superação da dicotomia entre homem e mundo. Ao romper com a ideia que situa quem conhece de um lado e o que é passível de ser 
conhecido do outro, Merleau-Ponty trabalhou com a dimensão do intersubjetivo, sendo a carne condição de possibilidade no contato com o outro. Coelho Junior (2003) afirma que a intersubjetividade demarca, na filosofia de Merleau-Ponty, uma indiferenciação entre o eu e o outro, enquanto que a intercorporeidade radicaliza essa relação, através da noção de carne. Essa noção de intercorporeidade remete a valorização da existência humana, se distanciando de uma posição filosófica que trata do sujeito representado.

Merleau-Ponty (1964/2012) refletiu que o olhar do homem sobre o mundo é ambíguo, formado na relação de atravessamento entre os objetos e os indivíduos, compreendendo que o

outro que me invade é todo feito de minha substância: suas cores, sua dor, seu mundo, precisamente enquanto seus, como os conceberia eu senão a partir das cores que vejo, das dores que tive, do mundo em que vivo? Pelo menos, meu mundo privado deixou de ser apenas meu; é, agora, instrumento manejado pelo outro, dimensão de uma vida generalizada que se enxertou na minha (p. 22).

Por não ser algo que possa ser observado e nem abstraído do mundo, a carne é algo que se vive, "já que o mesmo corpo vê e toca, o visível e o tangível pertencem ao mesmo mundo" (p. 131). O tocar é compreendido, aqui, como contemplando todos os sentidos, a visão, por exemplo, sendo a palpação do olhar. O sujeito encarnado está no mundo, este o atravessa, e as dimensões de espaço e tempo não são a soma de indivíduos locais e temporais.

Como as dimensões da universalidade e da particularidade são contempladas na filosofia de MerleauPonty (1964/2012) como carne, sua fenomenologia se encontra sempre em movimento de transformação, mundanamente constituída. O que é tomado como realidade não pertence a nenhuma particularidade, porém, isso "não me autoriza a romper ou silenciar a ligação que as reúne, uma após outra, ao real, que não pode ser rompida com uma, sem antes estabelecer-se com a seguinte" (p. 48). Com isso, o filósofo demarca sua posição ao reconhecer que não há algo puro, separado do mundo, diferente de uma filosofia reflexiva que "parte do princípio de que, se uma percepção deve poder ser minha, é preciso que, de agora em diante, seja uma de minhas 'representações', em outras palavras, que eu seja como pensamento" (p. 51).

A relação do homem com o mundo é marcada pela ambiguidade, não podendo entrar em competição com a visão do mundo pelos outros com aquela que tenho de mim mesmo. Na medida em que estou no mundo, o mundo está em mim e as noções de sujeito e objeto deixam de ser pré-estabelecidas. O corpo sente o mundo ao sentir-se, "as coisas passam por dentro de nós, assim como nós por dentro das coisas" (p. 121). Merleau-Ponty (1964/2012) orientou que o caminho para superar a divisão de minha consciência de e o objeto é compreender que essa minha consciência não é uma unidade, está a todo o momento sendo constituída, tanto pelo que se apresenta quanto por um mundo pré-reflexivo.

A reversibilidade é uma das características do ser carne, posso me sentir tocado ao mesmo tempo que toco, assim como posso falar tanto através do silêncio como com palavras, que expressam ideias e sentimentos. A esse movimento, Merleau-Ponty nomeou de quiasma, para refletir sobre termos que usualmente são apresentados como separados, como interior e exterior, homem e mundo, mas que ele os compreende como totalidade. Sua noção de carne se situa no próprio quiasma, ao não poder ser pensada "a partir das substâncias, corpo, espírito, pois seria então a união dos contraditórios, mas, dizíamos, como elemento, emblema concreto de uma maneira de ser geral” (p. 143). O quiasma é entrelaçamento, o olhar que constrói e é construído, considerando aquilo que se mostra sem ser visível a quem vê. 
A fenomenologia ambígua de Merleau-Ponty nos possibilita pensar diversas facetas sobre os fenômenos psicopatológicos, na medida em que toma as relações como totalidades que jamais se fecham, não compondo uma síntese. O conceito de Lebenswelt, em Merleau-Ponty (1964/2012), supera a cisão entre as dimensões do objetivo e do subjetivo, ao buscar o mundo vivido que se constrói em cada relação. Por o Lebenswelt surgir em uma condição de entrelaçamento entre homem e mundo, o filósofo alcançou aquilo que a princípio não seria possível apenas pela visão, substituindo o estudo do mundo ou da consciência, tradicionalmente investigado pelos filósofos que o antecederam, pelo ser pensado, não separando o observador daquilo que estava sendo observado.

Merleau-Ponty (1945/2011), já na Fenomenologia da Percepção, ao refletir sobre as manifestações de adoecimento, afirmava que "não podemos escolher entre uma descrição da doença que nos daria seu sentido e uma explicação que nos daria sua causa, e não há explicação sem compreensão" (p. 164). Observamos, aqui, sua compreensão ambígua da doença, ao buscar superar dicotomias, principalmente no que se refere à ideia de interioridade e exterioridade. Ao olhar para a totalidade do estar doente, a partir da filosofia de Merleau-Ponty, evidenciamos, nesta condição, uma perda de plasticidade do vivido, na medida em que, quando adoecido, não é possível, ao sujeito, uma mera expressão com o corpo, corpo e consciência existem entrelaçadas em um vivido singular.

\section{Interlocuções da filosofia de Merleau-Ponty com a psicopatologia fenomenológica de Arthur Tatossian}

A obra de Merleau-Ponty é atual, conforme faz reflexões sobre aspectos inerentes à existência humana, tais como as relações entre a objetividade e a subjetividade, sujeito e objeto, a temporalidade e a relação com o mundo e com o outro, possibilitando contribuições ao campo da psicopatologia fenomenológica. Tatossian (1979/2006), um dos principais representantes do desdobramento da fenomenologia no campo da psicopatologia fenomenológica, buscou alcançar, através do conceito de Lebenswelt, tanto a experiência anterior a qualquer julgamento que se tem diante da pessoa em sofrimento, quanto o Lebenswelt particular de cada vivido. Efetua, portanto, um duplo esforço ao visar o Lebenswelt: buscar a experiência pré-objetiva do sujeito e questionar como se constitui o Lebenswelt próprio de cada um (Moreira, 2011).

Ao pensarmos em processos patológicos, é fundamental compreendê-los como constituídos no entrelaçamento do homem com o mundo, a partir de cada modo de funcionamento. Para Tatossian (1997/2001), a expressão patológica era compreendida como a impossibilidade de se viver de maneira diferente, uma forma rígida de experiência que não permite o novo. O que é caracteristicamente patológico não se restringe aos comportamentos, mas é somente alcançado pelas modificações do vivido, em que deve ser considerado todo um conjunto de condições que o sustentam, avaliando o quanto o indivíduo perde autonomia e flexibilidade ao lidar com as situações de sua vida.

Tanto a manifestação do comportamento patológico quanto as teorias que o descrevem devem ser olhados como intrínsecos um ao outro, em um movimento ambíguo em que ao mesmo tempo constituem e são constituídos. Tatossian (1979/2006) considerava que, diferentemente do "trabalho especulativo sobre a literatura especializada, que foi o método de Merleau-Ponty e de outros também, deve preferir obrigatoriamente o comércio direto com o que está em questão: a loucura e o louco" (p. 29). Devido a então pouca penetração da fenomenologia no campo da psicopatologia, Tatossian afirmava que se devia estar sempre atento ao risco de se fazer uma mera aplicação da fenomenologia filosófica a uma prática clínica. Assim, compreendemos que, ao tomar a fenomenologia de Merleau- 
Ponty como um campo de implicação para pensar as expressões patológicas, jamais poderemos perder o contato com aquilo que se apresenta na experiência do homem em seu mundo.

A atitude fenomenológica permite sair do modo dualista de pensar e, a partir da filosofia de MerleauPonty, chegar a uma compreensão ambígua da relação homem-mundo, ou, poderíamos dizer, da relação homem-doença-mundo, considerando de modo complementar a relação entre teoria e prática e o movimento de descrição e busca da gênese, nos aspectos etiológicos dos fenômenos. Para Tatossian (1980/2012),

esta teoria fenomenológica que não sabe ou não quer engendrar prática específica, proclama também, de maneira muito firme e repetida, sua recusa precisamente de qualquer teoria, de qualquer prejulgamento na abordagem do homem doente e redizendo incansavelmente que a experiência concreta é não somente seu ponto de partida, mas igualmente seu ponto de chegada (p. 92).

Ao tomarmos a fenomenologia de Merleau-Ponty, a partir da perspectiva da psicopatologia fenomenológica de Tatossian, a consideramos no seu potencial de questionamento, indo além de um recurso metodológico, que atua apenas com o já dado. A relação entre teoria e prática, discutida por Tatossian, é construída como sendo de implicação e não de aplicação, na medida em que há um trabalho em fluxo que busca estar atento àquilo que se apresenta na experiência fenomenológica (Moreira, \& Bloc, 2012). Segundo Tatossian (1979/2006), “a fenomenologia não se interessa pelas realidades como tais, mas pelas suas condições de possibilidade" (p. 25). Buscar um olhar crítico no campo da psicopatologia é imprescindível, pois concebe o homem sempre em situação, não acreditando na existência de uma essência que o definiria (Moreira, 2004).

Para Tatossian (1979/2006), ao pensarmos os fenômenos psicopatológicos, é possível alcançarmos o mundo de significados dos modos de existência, partindo para a constituição do vivido. Tal movimento de buscar a origem se caracteriza como sendo o próprio Lebenswelt, já que o "Lebenswelt é mundo percebido por baixo das construções do pensamento" (p. 88-89). Ao intencionar alcançar o que está na ordem do pré-reflexivo, assumimos uma atitude implicada com a realidade para a qual nos voltamos, visando o Lebenswelt particular do indivíduo que sofre, o seu caráter de familiaridade, o meu mundo de cada indivíduo, sendo a "existência mundana vivida pelo indivíduo em sua unicidade" (p. 88). Essa unidade apenas se manifesta em uma experiência na qual sujeito e objeto, eu e mundo, não são colocados como isolados e opostos. O meu mundo individual e concreto também é o nosso mundo na medida em que está atrelado à historicidade e à intersubjetividade com a qual os indivíduos se constituem.

A experiência psicopatológica acontece na relação do empírico com o transcendental, o que resulta não em mera união dessas duas partes, mas na elaboração de algo novo e que é único em cada existência. Compreendemos que o que é pensado como patológico apenas é possível de ser considerado na relação, que permeia o campo da intersubjetividade. Ao construirmos uma interlocução entre a fenomenologia de Merleau-Ponty e a psicopatologia fenomenológica de Tatossian, a partir da relação entre homem e mundo, identificamos que ambos tomam a noção de Lebenswelt como um fio condutor que atravessa a forma como olham para tal relação. Mesmo que o filósofo não trabalhe com os conceitos de normal e patológico, por justamente buscar a suspensão de categorias que se afastam das coisas mesmas, Tatossian toma o que é considerado como norma para afirmar que nenhum fenômeno humano pode ser percebido isoladamente, já que, de outra maneira, não seria possível conhecê-lo. 


\section{Considerações finais}

Merleau-Ponty apontou o quanto somos aderentes ao mundo, na medida em que sentimos e vivemos um mundo próprio repleto de significações. Ao buscar superar a dicotomia entre homem e mundo, este filósofo possibilitou a existência de uma fenomenologia encarnada, que situa o mundo enquanto lugar de constituição, estando totalmente imbricado à experiência dos sujeitos.

Ao aproximarmos a fenomenologia de Merleau-Ponty à psicopatologia fenomenológica de Arthur Tatossian, compreendemos que para esses estudiosos o sofrimento humano é considerado para além da hegemonia do pensamento biológico, possibilitando uma visão menos dicotomizada diante da experiência com o outro. Se o mundo é campo da experiência, os indivíduos devem ser olhados sempre em situação, não sendo esta restrita a um espaço concreto, mas envolvendo todo um campo de significados.

O campo da psicopatologia fenomenológica, tal como pensado por Tatossian, busca a dimensão do pré-reflexivo, se aproximando do campo dos sentidos e também dos não sentidos, visando a presença do homem no mundo, através da tentativa de alcançar o Lebenswelt. Assim como na filosofia ambígua de Merleau-Ponty, que buscou romper com uma visão dicotômica do mundo, Tatossian, em sua psicopatologia fenomenológica, compreendeu ser indispensável o contato direto com a experiência, transcendendo a separação estanque entre teoria e prática ao pensar as teorias construídas sobre as manifestações psicopatológicas não a partir da experiência, mas na experiência. 


\section{Referências}

Coelho Junior, N. (2003). Da intersubjetividade a intercorporeidade: contribuições da filosofia fenomenológica ao estudo psicológico da alteridade. Psicologia USP, 14(1), 185-209.

Furlan, R., \& Bocchi, J. C. (2003). O corpo como expressão e linguagem em Merleau-Ponty. Estudos de Psicologia, 8(3), 445-450.

Merleau-Ponty, M. (2004). A dúvida de Cézanne. In Merleau-Ponty, M. O olho e o espírito. São Paulo, SP: Cosac \& Naify. (Originalmente publicado em 1945).

Merleau-Ponty, M. (2011). Fenomenologia da percepção (4a ed.). São Paulo, SP: Martins Fontes. (Originalmente publicado em 1945).

Merleau-Ponty, M. (2012). O visível e o invisível (Coleção Debates). São Paulo, SP: Perspectiva. (Originalmente publicado em 1964).

Moreira, V. (2004). O método fenomenológico de Merleau-Ponty como ferramenta crítica na pesquisa em psicopatologia. Psicologia: Reflexão e Crítica, 17(3), 447-456.

Moreira, V. (2007). De Carl Rogers a Merleau-Ponty: a pessoa mundana em psicoterapia. São Paulo, SP: Annablume.

Moreira, V. (2011). A contribuição de Jaspers, Binswanger, Boss e Tatossian para a psicopatologia fenomenológica. Revista da Abordagem Gestáltica, 17(2), 177-184.

Moreira, V., \& Bloc, L. (2012). Fenomenologia do tempo vivido no transtorno bipolar. Psicologia: Teoria e Pesquisa, 28(4), 443-450.

Schneider, D. (2009). Caminhos históricos e epistemológicos da psicopatologia: contribuições da fenomenologia e existencialismo. Cadernos Brasileiros de Saúde Mental, 1(2), $62-76$.

Tatossian, A. (2001). Cultura e psicopatologia: um ponto de vista fenomenológico. (J. C. Freire \& V. Moreira, Trads; V. Moreira, Rev. Técn.). Revista Latinoamericana de Psicopatologia Fundamental, 4(3), 137-144. (Originalmente publicado em 1997).

Tatossian, A. (2006). A fenomenologia das psicoses. (J. C. Freire, Trad., V. Moreira, Rev. Técn.). São Paulo, SP: Escuta (Originalmente publicado em 1979).

Tatossian, A. (2012). Teoria e prática em psiquiatria: sintoma e fenômeno, um ponto de vista fenomenológico. In A. Tatossian, \& V. Moreira, Clínica do Lebenswelt (pp. 91-100). São Paulo, SP: Escuta. (Originalmente publicado em 1980).

Tatossian, A., \& Moreira, V. (2012). Clínica do Lebenswelt. São Paulo, SP: Escuta. 